\title{
The Cross-Level Effect of Authentic Leadership on Teacher Emotional Exhaustion: The Chain Mediating Role of Structural and Psychological Empowerment
}

\author{
Zhihua $\mathrm{Xu}^{1}$ and Fu Yang ${ }^{2}$ \\ ${ }^{1}$ School of Law and Politics, Lingnan Normal University, Chikan, Zhanjiang, Guangdong Province, China \\ ${ }^{2}$ School of Business Administration, Southwestern University of Finance and Economics, Wenjiang, Chengdu, Sichuan Province, \\ China
}

\begin{abstract}
Ithough previous research has found that authentic leadership has a negative effect on employee burnout through structural empowerment, lack of psychological empowerment in the research cannot present a complete picture on how authentic leadership influences burnout because employees must experience being psychologically empowered for empowerment to be effective. Drawing on empowerment-related theories, this study integrates the three different perspectives of empowerment (authentic leadership, structural empowerment, and psychological empowerment) to examine their effects on emotional exhaustion, the core component of burnout, at multiple levels of analysis. Using a sample of 378 teachers from 59 primary and secondary schools in China, multilevel structural equation modelling results revealed that: (1) authentic leadership had an indirect effect on psychological empowerment partially through structural empowerment, (2) psychological empowerment played a full mediating role in the relationship between structural empowerment and emotional exhaustion, and (3) structural empowerment and psychological empowerment sequentially mediated the effect of authentic leadership on emotional exhaustion. Theoretical and practical implications are discussed.
\end{abstract}

Keywords: authentic leadership, structural empowerment, psychological empowerment, emotional exhaustion

Burnout is a syndrome characterised by the three components - emotional exhaustion, cynicism, and inefficacy — in response to chronic job stress (Leiter \& Maslach, 2004). An extensive body of research has demonstrated that employee burnout has negative effects on all sorts of personal and organisational wellbeing outcomes (e.g., Becker, Milad, \& Klock, 2006; Honkonen et al., 2006; Parker \& Kulik, 1995; Peterson et al., 2008). Therefore, it is of great importance to ascertain the antecedents to burnout and the relevant mechanisms to reduce its deleterious effect.

Previous research has demonstrated that positive forms of leadership matter in alleviating employees' burnout (e.g., Harms, Credé, Tynan, Leon, \& Jeung, 2017; Hildenbrand, Sacramento, \& Binnewies, 2018; Mo \& Shi, 2017; Yang \& Fry, 2018). Authentic leadership is an emerging leadership model and is considered to underlie various positive forms of leadership (Avolio \& Gardner, 2005). Several studies have revealed the effect of authentic leadership on burnout and its relevant mechanisms (e.g., Boamah, Read, \& Laschinger, 2017; Laschinger, Borgogni, Consiglio, \& Read, 2015; Laschinger, Wong, \& Grau, 2012, 2013).

Among these studies regarding the mechanisms whereby authentic leadership impacts burnout, it is worth noting that Laschinger et al. (2013) first explored the mechanism from the perspective of empowerment and found that authentic leadership had an indirect effect on nurses' emotional exhaustion and cynicism through structural empowerment. While admitting their contribution to the literature, we suggest that their model cannot comprehensively explain the psychological process of how

Address for correspondence: Fu Yang, School of Business Administration, Southwestern University of Finance and Economics, No. 555, Liutai Road, Wenjiang, Chengdu, Sichuan Province, 611130, China. Email: yfu@swufe.edu.cn 


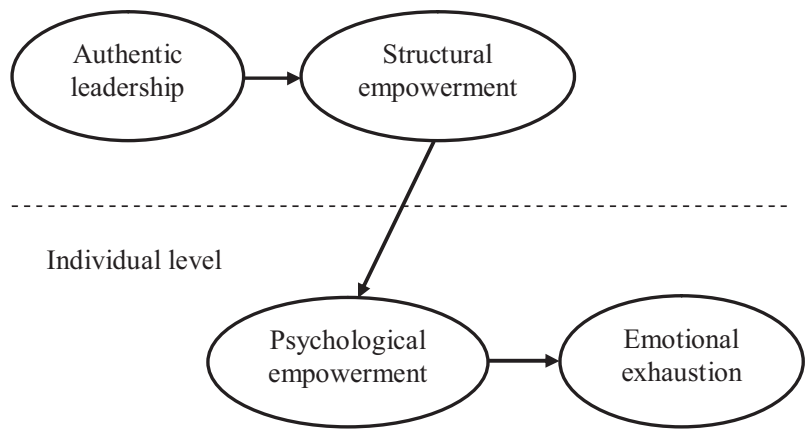

\section{Figure 1}

The hypothesised model.

authentic leadership impacts burnout from the perspective of empowerment. Three broad categories of empowerment - that is, leadership, structural, and psychological perspectives of empowerment - have been examined in the literature (Spreitzer, 1995). The leadership perspective of empowerment has emphasised the energising aspects of leaders' empowering styles and behaviours. In this regard, authentic leadership represents the leadership perspective of empowerment because authentic leaders are especially interested in energising and empowering their followers to make a difference (Gardner, Avolio, Luthans, May, \& Walumbwa, 2005; Ilies, Morgeson, \& Nahrgang, 2005; Luthans \& Avolio, 2003). From the structural perspective, structural empowerment focuses on policies and practices enacted by management aimed at transferring power from management to employees (Conger \& Kanungo, 1988). From a psychological perspective, psychological empowerment is defined as an individual's experience of intrinsic motivation that is based on four cognitions of one's work: meaning (i.e., value of work goal or work purpose), competence (i.e., self-efficacy), self-determination (i.e., choice about activities and work methods), and impact (i.e., influence on work outcomes; Spreitzer, 1996).

Although Laschinger et al. (2013) found that authentic leadership (i.e., the leadership perspective of empowerment) had an indirect impact on burnout through structural empowerment (i.e., the structural perspective of empowerment), the absence of psychological empowerment in the research means there is not a complete picture of how authentic leadership influences burnout because employees must experience being psychologically empowered for empowerment to be effective (Carless, 2004; Wallach \& Mueller, 2006). The model of empowerment process proposed by Conger and Kanungo (1988) reinforces this argument with the proposition that leadership influences individuals' outcomes by implementing empowerment practices and in turn eliciting the individuals' perceptions of psychological empowerment. Therefore, integrating the three different perspectives of empowerment (i.e., authentic leadership, structural empowerment, and psychological empowerment) and linking them to burnout is warranted.

In answering Walumbwa, Avolio, Gardner, Wernsing, and Peterson's (2008) call for a multilevel approach to examining authentic leadership, this study adopts a multilevel research design and draws on the model of empowerment process as a theoretical underpinning to posit the chain mediating role of structural and psychological empowerment in the relationship between authentic leadership and emotional exhaustion, the core element of burnout, conceptualising authentic leadership and structural empowerment as group-level constructs and psychological empowerment and emotional exhaustion as individual-level variables (Figure 1). In view that current studies have primarily focused on the effect of authentic leadership on nurses' burnout, this study uses a sample of primary and secondary school teachers to test the hypothesised model in Figure 1, thus contributing to the literature by showing a comprehensive process of how authentic leadership impacts teacher emotional exhaustion from the perspective of empowerment.

\section{Literature Review and Hypotheses Development}

\section{Authentic Leadership, Structural Empowerment, and Psychological Empowerment}

Authentic leadership is defined as 'a pattern of leader behavior that draws upon and promotes both positive psychological capacities and a positive ethical climate, to foster greater self-awareness, an internalised moral perspective, balanced processing of information, and relational transparency on the part of leaders working with followers, fostering positive self-development' (Walumbwa et al., 2008, p. 94), and is composed of four components: selfawareness, relationship transparency, balanced processing, and internalised moral perspective. Self-awareness refers to leaders understanding their strengths, weaknesses and motives, as well as recognising how others view their leadership. Relationship transparency involves 
leaders openly sharing information and expressing their true thoughts and feelings. Balanced processing denotes that leaders objectively analyse all relevant information and solicit views that challenge their deeply held positions before coming to a decision. An internalised moral perspective entails leader behaviours that are guided by internal moral standards and values rather than by group, organisational, and societal pressures. Conceptualising authentic leadership as a group-level construct means that members in the same group share similar perceptions regarding the extent to which their leader exhibits authentic leadership behaviour.

Kanter's (1993) theory of structural empowerment describes four organisational empowerment structures: access to information, support, resources, and opportunities. Having access to these structures is influenced by formal and informal power systems. Formal power is evident in jobs that are flexible, visible, and central to the organisation's goal and supports employee creativity and discretionary decision making. Informal power is derived from close contacts and social alliances with sponsors, peers, and subordinates both within and outside the organisation. Structural empowerment is high when employees have access to these empowerment structures in the workplace. Structural empowerment conceptualised as a group-level variable is also termed as empowerment climate, which entails that members in the same group share similar perceptions of managerial structure, policies, and practices related to empowerment because the social processes take place within the group (Seibert, Silver, \& Randolph, 2004).

Because leaders implement organisational policies and model desired behaviours, they behave as 'climate engineers' to shape employees' perceptions of their organisation (Naumann \& Bennett 2000). Following this logic, we view authentic leadership as contributing to team members' shared perceptions of empowerment (i.e., empowerment climate or structural empowerment at the group level). Authentic leadership behaviours demonstrated by a team leader allow team members to have access to information, support, resources, and opportunities to learn and develop, which constitute empowering structures in the team. Authentic leaders encourage followers to openly share information and tell their true thoughts and feelings, making information flow all around and enabling followers to readily obtain information required to be effective at work. Authentic leaders provide employees with opportunities for sustained development and growth by helping them discover their talents, developing these into strengths, and empowering them to do tasks at which they are good (Luthans \& Avolio, 2003). Authentic leaders support autonomy and provide non-controlling positive feedback (Ilies et al., 2005). Authentic leaders establish an authentic relationship with followers characterised by transparency, openness and trust (Gardner et al., 2005), which creates more opportunities for group members observing and interacting with their leaders to interpret group and organisation practices, as well as sharing and clarifying perceptions (Kozlowski \& Doherty, 1989). According to Dragoni (2005), the effect of leadership on group climate is a social learning process in which group members repeatedly observe and interact with their leader to interpret group and organisation practices. Therefore, when authentic leaders persistently promote empowerment structures, subordinates are well informed that empowerment is prioritised, valued and supported, promoting the development of shared cognitions of empowerment in the workplace because of the commonality of the leaders' messages and practices (Zohar \& Tenne-Gazit, 2008), which constitutes the empowerment climate, that is, structural empowerment at the group level. Thus, we propose the following hypothesis.

Hypothesis 1: Authentic leadership is positively related to structural empowerment at the group level.

The theory of structural empowerment claims that management can empower employees by ensuring that they have access to information, support, resources, and opportunities to learn and grow, that is, establishing empowering structures in the workplace, which in turn shape work attitudes and behaviours (Kanter, 1993). Gardner et al. (2005) suggested that in order to elicit positive outcomes, authentic leaders should provide an empowerment climate that gives full access to information, support, resources, and opportunities to learn and develop. Some studies evidenced the above arguments with the findings that structural empowerment mediated the relationships both between transformational leadership and psychological empowerment and between authentic leadership and relational social capital (Sun, Zhang, Qi, \& Chen, 2012; Read \& Laschinger, 2015). Thus, we view structural empowerment as an important mechanism whereby leadership in general, and authentic leadership in particular, influences employee psychological empowerment.

As postulated by Hypothesis 1, authentic leadership fosters an empowerment climate in the group, which according to relevant theoretical and empirical findings would elicit individuals' perceptions of psychological empowerment. Social structures in the workplace have a greater impact on employee work attitudes and behaviours than do personality and socialisation experiences (Kanter, 1993), and an extensive research has found that organisational climate perceptions are associated with individual attitudes and behaviours (e.g., Hofmann \& Stetzer, 1996; Schneider, Parkington, \& Buxton, 1980). Therefore, we expect that an empowerment climate (i.e., structural empowerment at the group level) is related to individuallevel perceptions of psychological empowerment. Tuuli and Rowlinson (2009) distinguished structural empowerment and psychological empowerment in referent, focus, and content. Whereas structural empowerment is the perception of the presence or absence of empowering work conditions, psychological empowerment is employees' psychological interpretation or reaction to these 
empowering conditions. In other words, structural empowerment is an antecedent of psychological empowerment. Prior research has found a positive link from structural empowerment to psychological empowerment (Laschinger, Finegan, Shamian, \& Wilk, 2004; Seibert et al., 2004; Tuuli \& Rowlinson, 2009). Combining the above arguments on the relationships both between authentic leadership and structural empowerment and between structural empowerment and psychological empowerment, we offer the following hypothesis.

Hypothesis 2: Structural empowerment mediates the relationship between authentic leadership and psychological empowerment.

\section{Structural Empowerment, Psychological Empowerment, and Emotional Exhaustion}

Psychological empowerment is viewed by empowerment theorists as the mechanism through which contextual factors influence individual attitudes and behaviours (Spreitzer, 1995, 1996; Thomas \& Velthouse, 1990). For example, Thomas and Velthouse (1990) claimed that environmental events providing an individual with data about the consequences of ongoing task behaviour and about the future behaviour-related conditions and events shape the individual's task appraisals regarding meaningfulness, competence, impact, and choice, which in turn energise and sustain the individual's behaviour. Several studies integrating social-structural and psychological empowerment indicated that the effects of structural empowerment on performance and wellbeing are mediated by psychological empowerment (e.g., Biron \& Bamberger, 2010; Laschinger, Finegan, \& Shamian, 2001; Seibert et al., 2004). Therefore, we expect that empowering environmental structures would elicit employees' perceptions of being empowered, which in turn would decrease their emotional exhaustion.

As noted above, psychological empowerment represents the psychological interpretation or reaction to structural empowerment, and there is positive relationship between these empowerments. Next, we draw on the demand-control model (DCM) and the personenvironment fit theory to develop the hypothesised negative relationship between psychological empowerment and emotional exhaustion. The DCM postulates that high job demands lead to high strain, especially when an employee has a lack of control over his or her job (Karasek, 1979). Control, which is the extent to which an individual influences which work is to be done and how, and which is conceptually similar to the psychological empowerment facets of self-determination and impact, provides the individual with cognitive, affective, and motivational resources to combat high job demands (Schermuly \& Meyer, 2016). Thus, in the framework of the DCM, psychological empowerment can be seen as an important resource to reduce high experienced job demands that would drain one's physical and emotional resources to cause him or her emotional exhaustion. The person-environment fit theory assumes that a fit between the characteristics of the job and the characteristics of the person decreases strain (French, Rodgers, \& Cobb, 1974; Harrison, 1978). Therefore, finding the value of a work goal or a work purpose judged in relation to one's ideals or standards (meaning) or feeling one's own abilities to reach the job requirements (competence) helps to reduce one's emotional exhaustion. Several studies provide empirical support for the negative relationship between psychological empowerment and emotional exhaustion (Hochwälder, 2007; Hochwälder \& Brucefors, 2005; Rantika \& Yustina, 2017). Combining the above arguments on the relationships both between structural empowerment and psychological empowerment and between psychological empowerment and emotional exhaustion, we propose the following hypothesis.

Hypothesis 3: Psychological empowerment mediates the relationship between structural empowerment and emotional exhaustion.

The model of empowerment process suggests that managers should use empowerment practices aimed at not only removing external conditions responsible for powerlessness but also at providing subordinates with self-efficacy information that results in empowering experiences of the subordinates that in turn leads to their behaviour effects (Conger \& Kanungo, 1988). Consistent with the argument, Sun et al. (2012) found that transformational leadership influenced subordinate creativity through the sequential mediation role of structural empowerment and psychological empowerment. Therefore, integrating Hypotheses 1,2 and 3, we expect that structural empowerment and psychological empowerment may play the chain mediating role between authentic leadership and emotional exhaustion.

Hypothesis 4: Structural empowerment and psychological empowerment sequentially mediate the relationship between authentic leadership and emotional exhaustion.

\section{Methods}

\section{Sample and Procedure}

We contacted the principals at 59 primary and secondary schools located in the Guangdong province of the People's Republic of China and informed them of the objective of this study. With the principals' consent, we met with the teachers in these schools, distributed questionnaires to them, and collected the data on site. A cover letter attached to every questionnaire explained the objective of the survey, assured anonymity and confidentiality, and informed the voluntary nature of participation in this study. To facilitate participation, each teacher was given a small gift.

A total of 412 questionnaires were distributed, of which 406 were returned. Eliminating the participants with missing data resulted in 378 teachers from 59 schools. Regarding the individual-level data, $60.1 \%$ of the participants 
were female; $76.2 \%$ were married; $3.4 \%$ had a technical school or high school diploma, $27 \%$ had college diploma, $69.3 \%$ had a bachelor's degree, and $0.3 \%$ had a graduate degree; $27.2 \%$ had taught for $0-5$ years, $17.2 \%$ for 6-10 years, $17.5 \%$ for $11-15$ years, $18.8 \%$ for $16-20$ years, and $19.3 \%$ for 21 and above years. Regarding the grouplevel data, $61.4 \%$ of the participating schools were primary schools, $23.5 \%$ were junior high schools, and $15.1 \%$ were senior high schools; the average number of research participants was 6.4 (ranging from 2 to 36 ) from each school.

\section{Measures}

The measures of authentic leadership and structural empowerment were originally constructed in English and translated into Chinese by performing a standard translation and back-translation procedure to ensure measurement equivalence (Brislin, 1980). Unless otherwise indicated, the response scale was from 1 (strongly disagree) to 5 (strongly agree).

Authentic leadership. Authentic leadership was measured using the 16-item Authentic Leadership Questionnaire developed and validated by Walumbwa et al. (2008). Teachers were asked to rated their principals' authentic leadership behaviors on a 5-point Likert scale. Sample items include 'Is eager to receive feedback to improve interaction with others' (self-awareness), 'Solicits views that challenge his or her deeply held positions' (balanced processing), 'Makes decisions based on his/her core beliefs' (internalised moral perspective), 'Is willing to admit mistakes when they are made' (relational transparency). The coefficient alpha for this scale was 0.96. Because we conceptualised authentic leadership as a group-level construct, we aggregated individual-level perceptions of authentic leadership to the group level. To support our aggregation decision, we calculated within-group agreement index $r_{\text {wg }}$ and intraclass correlation coefficients ICC (1) and ICC (2). We obtained an average $r_{\mathrm{wg}}$ of $.97(M d n=0.98$, range $=0.85$ $1)$, using a uniform null distribution, an ICC (1) of 0.46 , and an ICC (2) of 0.84 (Bliese, 2000), and an analysis of variance (ANOVA) indicating a significant between-group variance, $F(58,319)=6.38, p<0.001$, all supporting this aggregation.

Structural empowerment. The 19-item Conditions of Work Effectiveness Questionnaire-II (CWEQ-II) was adapted to measure structural empowerment (Laschinger, Finegan, Shamian, \& Wilk, 2001). Sample items include 'My job gives me the chance to gain new skills and knowledge' (access to opportunity), 'I know the values of top management' (access to information), 'I can have access to helpful hints or problem solving advice' (access to support), 'I have time available to accomplish my job requirements' (access to resources), 'My innovation on the job is rewarded' (formal power), and 'I am sought out by peers for help with problems' (informal power). The coefficient alpha is 0.91 . Because conceptualising structural empowerment as a shared perception of a work unit, we aggregated the individual-level scores to the group level. In support of this aggregation, we obtained an average $r_{\mathrm{wg}}$ of $0.98(M d n=0.99$, range $=0.86-1)$, using a uniform null distribution, an ICC(1) of 0.29 , an $\operatorname{ICC}(2)$ of 0.72 (Bliese, 2000), and a significant between-group variance, $F(58,319)=3.51, p<0.001$.

Psychological empowerment. We measured psychological empowerment using a 12-item scale developed by Spreitzer (1995) and translated into Chinese by Li, Li, Shi, and Chen (2006). Sample items include 'The work I do is very important to me' (meaning), 'I am confident about my ability to do my job' (competence), 'I have significant autonomy in determining how I do my job' (selfdetermination), and 'My impact on what happens in my school is large' (impact). The overall reliability coefficient for this scale was 0.86 .

Emotional exhaustion. To measure emotional exhaustion, we used the Chinese version of the 10-item emotional exhaustion subscale of burnout developed by Wang, Zhang, Gan, and Zhang (2005). A sample item reads 'I feel burnt out from my job’. Cronbach's alpha was 0.89 .

Control variables. We controlled for a number of individual-level demographic variables including gender ( $1=$ male, $0=$ female $)$, marital status $(1=$ married, $0=$ unmarried $)$, education degree $(1=$ technical school or high school, $2=$ college, $3=$ bachelor, and $4=$ graduate), and years of teaching ( $1=0-5$ years, $2=6-10$ years, $3=11-15$ years, $4=16-20$ years, and $5=21$ and above years). We also controlled for the group-level variable of school type ( $1=$ primary school, $2=$ junior high school, and $3=$ senior high school). Because education degree, years of teaching, and school type are categorical variables with more than two levels, these variables were transformed into dummy variables before testing the hypotheses: 3 dummy variables for education degree, 4 for years of teaching, and 2 for school type, using technical school or high school, 0 to 5 years, and primary school as referent groups respectively.

\section{Analytic Strategy}

Taking into account the nested nature of the data (i.e., teachers were nested within principals), we used multilevel structural equation modelling (MSEM) to test these hypotheses. When testing mediation effects, MSEM is superior to the hierarchical linear modelling (HLM) approach that applies Baron and Kenny's (1986) multistep regressions into the multilevel setting (Preacher, Zyphur, \& Zhang, 2010). Specifically, as compared to the HLM approach, MSEM can directly estimate mediation effects and the multiple paths that constitute these mediation effects, add information on how the hypothesised model fits the data, and prevent conflating between-group and withingroup relationships (Sun et al., 2012). We performed the analyses using Mplus 7.0 (Muthen \& Muthen, 1998-2012) with robust full maximum likelihood (MLR) estimation. 
Table 1

Means, Standard Deviations, Reliabilities and Correlations Among the Study Variables

\begin{tabular}{lllllll}
\hline & Mean & $S D$ & 1 & 2 & 3 & 4 \\
\hline 1. Authentic leadership & 3.97 & 0.66 & $(0.96)$ & & & \\
2. Structural empowerment & 3.77 & 0.48 & $0.59^{* *}$ & $(0.91)$ & & \\
3. Psychological empowerment & 3.73 & 0.51 & $0.60^{* *}$ & $0.66^{* *}$ & $(0.86)$ & $(0.89)$ \\
4. Emotional exhaustion & 2.79 & 0.73 & $-0.15^{* *}$ & $-0.41^{* *}$ & $-0.29^{* *}$ &
\end{tabular}

Note: All correlations are at the individual level. Reliability estimates are listed in the parentheses along the diagonal $(N=378)$.

** $p<.01$ (two-tailed).

Table 2

Results for MSEM Comparison

\begin{tabular}{|c|c|c|c|c|c|c|}
\hline Model & $x^{2}$ & $d f$ & CFI & TLI & RMSEA & $\operatorname{TRd}(\Delta d f)$ \\
\hline Hypothesised model (see Figure 1) & 534.42 & 279 & 0.89 & 0.87 & 0.049 & \\
\hline Alternative model 1 (adding a direct path from authentic leadership to emotional exhaustion) & 531.93 & 278 & 0.89 & 0.87 & 0.049 & $2.49(1)$ \\
\hline Alternative model 2 (adding a direct path from structural empowerment to emotional exhaustion) & 534.04 & 278 & 0.89 & 0.87 & 0.049 & $0.38(1)$ \\
\hline Alternative model 3 (adding a direct path from authentic leadership to psychological empowerment) & 520.41 & 278 & 0.90 & 0.88 & 0.048 & $14.01(1)^{* * *}$ \\
\hline
\end{tabular}

Note: TRd $=$ Satorra-Bentler scaled chi-square difference.

**** $p<.001$.

\section{Results}

\section{Common Method Variance Assessing}

Because self-reported data were used in this study, Harman's single-factor test was performed to examine the possible issue of common method variance (CMV; Podsakoff, MacKenzie, Lee, \& Podsakoff, 2003). Unrotated principal component factor analysis showed that $10 \mathrm{fac}-$ tors accounted for $64.37 \%$ of the variance and that the first largest factor accounted for $30.45 \%$ of the variance, less than $40 \%$. Therefore, we suggested that CMV was not a major issue in this study.

\section{Confirmatory Factor Analysis and Descriptive Statistics}

We conducted confirmatory factor analysis (CFA) at the individual level to verify the discriminative validity of the four employee self-reported variables, including authentic leadership, structural empowerment, psychological empowerment, and emotional exhaustion. Consistent with prior research (Hisung, 2012; Leroy, Anseel, Gardner, \& Sels, 2015), we used item parcels to maintain an appropriate indicator-to-sample-size ratio. Following the recommendations by Little, Cunningham, Shahar, and Widaman (2002), we created four domain-representative parcels for authentic leadership and psychological empowerment and six for structural empowerment, and did five random parcels for emotional exhaustion. Results revealed that the four-factor model fitted the data well $\left(\chi^{2}=425.66\right.$, $d f=146, \mathrm{TLI}=0.93, \mathrm{CFI}=0.94, \mathrm{RMSEA}=0.07)$. Model comparison indicated that this model fitted the data better than any of the alternative models: the two-factor model A (structural empowerment and psychological empowerment were combined into a single factor; $\Delta \chi^{2}=92.35$, $\Delta d f=3, p<.001$ ), the two-factor model B (authentic leadership and structural empowerment were combined into a single factor; $\Delta \chi^{2}=679.04, \Delta d f=3, p<.001$ ), the two-factor model $\mathrm{C}$ (authentic leadership and psycho- logical empowerment were combined into a single factor; $\left.\Delta \chi^{2}=231.26, \Delta d f=3, p<.001\right)$, and one-factor model (all constructs were combined into a single factor; $\Delta \chi^{2}=$ $1762.68, \Delta d f=3, p<.001)$. Table 1 presents means, standard deviations, correlations, and internal consistent reliabilities of all the study variables.

\section{Hypotheses Testing}

Before analysing cross-level effects, two null model estimations were used to test the significant level of betweengroup variances in psychological empowerment and emotional exhaustion. The results showed that $24 \%$ of the variance in emotional exhaustion and $23 \%$ of the variance in psychological empowerment resided between groups and that between-group differences in average scores for these two variables were all significant and meaningful $(p<.01 ; p<.001)$, indicating that group-level factors were meaningful for explaining these two individual-level variables.

Using MSEM and the same item parcels as the above CFAs, we tested our hypotheses through a series of nested model comparisons. Mplus output warned that the chisquare value for MLR cannot be used for chi-square difference testing in the regular way and instructed us to follow the two steps described on the Mplus website to compute the Satorra-Bentler scaled chi-square difference TRd. As shown in Table 2, the hypothesised model (as shown in Figure 1) had an acceptable fit to the data $\left(\chi^{2}=\right.$ 534.42, $d f=279$, CFI $=0.89$, TLI $=0.87$, RMSEA $=$ 0.049 ). In the first alternative model, we added a direct path from authentic leadership to emotional exhaustion. The results showed that this model did not significantly differ from the hypothesised model (TRd [1] $=2.49, n s$ ) and that the path from authentic leadership to emotional exhaustion was not significant, providing support for the hypothesised model. We added a direct path from 
Table 3

Results for Testing the Hypotheses

\begin{tabular}{|c|c|c|c|}
\hline Path & Estimate & $\begin{array}{l}\text { estimate/ } \\
\text { standard error }\end{array}$ & $\begin{array}{l}95 \% \text { confidence } \\
\text { interval }\end{array}$ \\
\hline \multicolumn{4}{|l|}{ Direct effects } \\
\hline \multicolumn{4}{|l|}{ Between-group direct path (Hypothesis 1) } \\
\hline Authentic leadership $\rightarrow$ structural empowerment & $0.45^{* * *}$ & 5.64 & {$[0.30,0.61]$} \\
\hline \multicolumn{4}{|l|}{ Cross-level direct path } \\
\hline Structural empowerment $\rightarrow$ psychological empowerment & $0.40^{*}$ & 2.49 & {$[0.09,0.71]$} \\
\hline Authentic leadership $\rightarrow$ psychological empowerment & $0.24^{* *}$ & 2.99 & {$[0.08,0.40]$} \\
\hline \multicolumn{4}{|l|}{ Within-group direct path } \\
\hline Psychological empowerment $\rightarrow$ emotional exhaustion & $-0.46^{* * *}$ & -3.48 & {$[-0.72,-0.20]$} \\
\hline \multicolumn{4}{|l|}{ Between-group direct path } \\
\hline Psychological empowerment $\rightarrow$ emotional exhaustion & $-0.70^{*}$ & -2.49 & {$[-1.24,-0.15]$} \\
\hline \multicolumn{4}{|l|}{ Indirect effects } \\
\hline Authentic leadership $\rightarrow$ structural empowerment $\rightarrow$ psychological empowerment (Hypothesis 2 ) & $0.18^{* *}$ & 2.73 & {$[0.05,0.31]$} \\
\hline Structural empowerment $\rightarrow$ psychological empowerment $\rightarrow$ emotional exhaustion (Hypothesis 3$)^{a}$ & $-0.28^{\dagger}$ & -1.65 & {$[-0.60,0.05]$} \\
\hline $\begin{array}{l}\text { Authentic leadership } \rightarrow \text { structural empowerment } \rightarrow \text { psychological empowerment } \rightarrow \text { emotional } \\
\text { exhaustion (Hypothesis } 4)^{b}\end{array}$ & $-0.13^{\dagger}$ & -1.68 & {$[-0.27,0.02]$} \\
\hline Authentic leadership $\rightarrow$ psychological empowerment $\rightarrow$ emotional exhaustion & $-0.17^{*}$ & -2.44 & {$[-0.30,-0.03]$} \\
\hline
\end{tabular}

structural empowerment to emotional exhaustion to form the second alternative model. This model showed no significant difference in model fit compared to the hypothesised model (TRd [1] $=0.38, n s$ ); moreover, the added path from structural empowerment to emotional exhaustion was insignificant, these results indicating that the hypothesised model was more parsimonious and fitted the data better than the second alternative model. In the third alternative model, a direct path from authentic leadership to psychological empowerment was added. This model showed a significant change in the Satorra-Bentler scaled chi-square (TRd [1] $=14.01, p<.001$ ) and had better fit indices compared to the hypothesised model $\left(\chi^{2}=\right.$ 520.41, $d f=278$, CFI $=0.90$, TLI $=0.88$, RMSEA $=$ 0.048 ); moreover, the added path from authentic leadership to psychological empowerment was significant and in the expected direction. Therefore, we concluded that alternative model 3 provided the best fit to our data and was used to test our hypotheses.

Table 3 presents the direct and indirect effects based on alternative model 3. Estimate, estimate/standard error, and 95\% confidence interval for each direct and indirect effect are reported. Hypothesis 1 predicted that authentic leadership was positively associated to group structural empowerment. As shown in Table 3, the direct path from authentic leadership to structural empowerment was significant $(b=0.45, p<.001,95 \%$ CI $[0.30,0.61])$. Hence, Hypothesis 1 was supported.

Hypothesis 2 predicted that structural empowerment mediated the relationship between authentic leadership and psychological empowerment. As shown in Table 3, the indirect effect of authentic leadership on psychological empowerment through structural empowerment was significant $(b=0.18, p<.01,95 \%$ CI $[0.05,0.31])$. Given that the direct path from authentic leadership to psychological empowerment was significant $(b=0.24, p<.01,95 \% \mathrm{CI}$ $[0.08,0.40])$, it can be concluded that structural empowerment played a partial mediation role between authentic leadership and psychological empowerment. Hence, Hypothesis 2 was supported.

Hypothesis 3 predicted that the cross-level effect of structural empowerment on emotional exhaustion was mediated by psychological empowerment. Zhang, Zyphur, and Preacher (2009) argued that cross-level mediation effects may be confounded if one looks at within-group effects as mediators rather than between-group effects. As such, we specified calculating the cross-level mediation effect with the between-group effect of psychological empowerment on emotional exhaustion rather than the within-group effect of that. As shown in Table 3, the indirect effect via psychological empowerment was marginally significant when we used a two-tailed test $(b=-0.28$, $p<.1,95 \%$ CI $[-0.60,0.05])$. However, this indirect effect was significant when we used a single-tailed test $(b=$ $-0.28, p<.1,90 \%$ CI $[-0.55,-0.00])$ and consistent with Hypothesis 3 in the predicted direction. Thus, we suggest that Hypothesis 3 was supported. Since structural empowerment was not directly related to emotional exhaustion, psychological empowerment fully mediated this relationship.

Hypothesis 4 predicted that the relationship between authentic leadership and emotional exhaustion was sequentially mediated by structural empowerment and psychological empowerment. As Table 3 shows, although this chain mediation effect was marginally significant when using a two-tailed test $(b=-0.13, p<.1,95 \%$ CI $[-0.27$, $0.02])$, it was significant when using a single-tailed test $(b=-0.13, p<.1,90 \%$ CI $[-0.25,-0.00])$ and consistent with Hypothesis 4 in the predicted direction. Hence, Hypothesis 4 was supported. As shown in Table 3, in addition 
to the chain mediation effect of structural empowerment and psychological empowerment, the indirect effect of authentic leadership on emotional exhaustion through psychological empowerment was also significant $(b=-0.17$, $p<0.05,95 \%$ CI $[-0.30,-0.03])$.

\section{Discussion}

\section{Theoretical Implications}

This study expands on previous research into the effects of empowerment in several ways. First, a novel finding of our study was that authentic leadership has a positive effect on group empowerment climate, in addition to its effect on the positive affective tone of the team (Hmieleski, Cole, \& Baron, 2012), safety climate (Borgersen, Hystad, Larsson, \& Eid, 2014), and justice climate (Hsiung, 2012; Kiersch \& Byrne, 2015). According to Dragoni (2005), we suggest that the relationship between authentic leadership and structural empowerment at the group level can be explained as a social learning process, that is, when authentic leaders model constantly building empowerment structure in the group, group members recognise that empowerment is prioritised, valued, and supported in the group, promoting the shared perceptions of empowerment among the group members, hence the emergence of the group empowerment climate. Second, by examining the mediating role of structural empowerment in the relationship between authentic leadership and psychological empowerment, this study extends previous research on the effect of authentic leadership on psychological empowerment. Although the main effect of authentic leadership on psychological empowerment was found in some studies (e.g.) Shapira-Lishchinsky \& Tsemach, 2014; Walumbwa, Wang, Wang, Schaubroeck, \& Avolio, 2010; Zhang, Song, Wang, \& Liu, 2018), our study is among the first to identify the mediating mechanism. Extending the previous research on examining the relationships between authentic leadership and structural empowerment (e.g., Laschinger et al., 2013; Read \& Laschinger, 2015) or psychological empowerment (e.g., Walumbwa et al., 2010; Shapira-Lishchinsky \& Tsemach, 2014; Zhang et al., 2018), this study integrates the three different perspectives of empowerment - authentic leadership (as the leadership aspect of empowerment), structural empowerment (i.e., empowerment climate), and psychological empowerment - at multiple levels and shows that authentic leadership fosters the group empowerment climate, which in turn shapes individual perceptions of psychological empowerment, thus adding to the knowledge of the specific effects of various empowerments at multiple levels of analysis. Third, by examining the cross-level mediation effect of structural empowerment at the group level on emotional exhaustion through psychological empowerment, this study unveils the process regarding how empowerment climate influences emotional exhaustion. Consistent with the previous findings of psychological empowerment as a mechanism whereby structural empow- erment affects organisational- and personal-related outcomes (e.g., Biron \& Bamberger, 2010; Laschinger et al., 2001; Seibert et al, 2004), our study provides evidence for the proposition that structural empowerment has an indirect effect on emotional exhaustion through psychological empowerment. However, our study is among the first to test the proposition at multiple levels of analysis. Fourth, this study provides new insight into how authentic leadership influences emotional exhaustion. Extending previous research with structural empowerment as a sole mediator in the relationship between authentic leadership and emotional exhaustion (Laschinger et al., 2013), this study incorporates structural empowerment and psychological empowerment and reflects that authentic leadership influences emotional exhaustion through group-level structural empowerment and individual-level psychological empowerment in sequence. Therefore, it gives a more comprehensive account of the process of the trickle-down effect of empowerment on emotional exhaustion and provides further evidence for the model of empowerment process, in addition to Sun et al. (2012)'s findings. Additionally, given that previous studies mostly focused on the relationship between authentic leadership and burnout among nurses (e.g., Boamah et al., 2017; Laschinger et al., 2015), the findings in this study underscore the generalisability of the effect of authentic leadership on burnout in non-health-care professional groups.

\section{Practical Implications}

Our findings show that authentic leaders can enhance individuals' experience of empowerment by implementing empowering practices and creating an autonomous work environment, suggesting that empowerment originates from leadership and that increased empowerment can be achieved through enhancing authentic leadership. For example, we can obtain more authentic leaders by selecting and promoting individuals who possess the characteristics underlying each of the components of authentic leadership (Ilies et al., 2005). Because individuals with a positive self-concept have a better self-awareness and emotionally intelligent individuals understand themselves and their own emotions more, the individuals who score high in these individual differences of positive self-concept and emotional intelligence should be selected and promoted to leading posts. Also, organisations can obtain more authentic leaders by implementing some developmental initiatives to foster each of the components of authentic leadership (Ilies et al., 2005). For example, multisource feedback (from followers, peers, and supervisors) can be utilised to enhance a leader's self-awareness because it enables them to have a greater understanding of how he or she is perceived by others and eliminate potential discrepancy between self-perceptions and others' perceptions.

The findings also indicate that authentic leadership may decrease followers' emotional exhaustion by fostering empowering work conditions and further increasing 
the followers' empowerment experience. For less emotional exhaustion to be experienced, leaders should foster work environments that empower and enable followers to accomplish their work. Leaders should provide their followers with information about organisational values, goal, and policies. By gaining organisation-relevant information such as its strategy and goals, individuals may feel psychological ownership of the organisation, have the knowledge of how their work roles and behaviours have an impact on its success, and make autonomous choices beneficial for the organisation (Spreitzer, 1996). Leaders should provide their followers with various supports, including feedback, guidance, and emotional support. By taking time to have a dialogue about a subordinate's strengths and how these can be brought into full play, a leader can build a closer connection with the subordinate that leads to his or her personal identification with and feeling of psychological empowerment from the leader (Walumbwa et al., 2010). Leaders should provide their followers with challenges, rewards, and professional development opportunities to increase knowledge and skills. By helping them discover their talents, developing them into strengths, and empowering them to perform tasks at which they are adept, leaders can meet followers' needs for competence and autonomy (Gardner et al., 2005). Finally, leaders should provide employees with various resources, such as materials, money, supplies, time, and the equipment required to accomplish organisational goals to promote employee empowerment.

\section{Limitations and Future Directions}

Notwithstanding its theoretical contributions and practical implications, this study has some limitations that should be noted. First, because a cross-sectional design was used in this study, we cannot conclusively draw causal inferences about the relationships among the examined variables. Thus, a longitudinal design should be used in future research to confirm the causality among the variables examined in this study. Second, the self-reported data in our study raises a concern over CMV. However, we suggest that CMV has little impact on our findings based on the following reasons. Although we obtained the data from the teachers' self-reports, the individual-level data of authentic leadership and structural empowerment were aggregated to the group level, which would address the issue of CMV because the individual differences in authentic leadership and structural empowerment were treated as an error when averaging these individual-level data to the group level (Bono \& Judge, 2003). Moreover, the results of the CFAs and Harman's single-factor test indicated that CMV was not a major issue in this study. Nevertheless, future research should collect data from different sources at different time periods to further mitigate concern over CMV. In addition, because structural empowerment is more objective than psychological empowerment, future research should use an objective measure of structural empowerment to replicate and extend the current study. A final limitation is about whether our findings could extend to other cultural contexts besides China's. Followers' reactions in high power distance cultures like China may depend more on the relational aspects of the treatment by their leaders, such as neutrality, trustworthiness and respect for their rights, while their counterparts in low power distance cultures tend to maintain a more formal relationship with their supervisors that could limit meaningful interactions with the supervisors. As a result, authentic leaders who show care and respect for their followers may have a stronger effect on follower outcomes in high power distance cultures than in low power distance cultures (Walumbwa et al., 2010). Therefore, future research should examine the influences societal culture differences may have on our findings.

\section{Funding}

This study was funded by the Lingnan Normal University Special Project for Talents (Grant number ZW1803).

\section{References}

Avolio, B.J., \& Gardner, W.L. (2005). Authentic leadership development: Getting to the root of positive forms of leadership. The Leadership Quarterly, 16, 315-338.

Baron, J.N., \& Kenny, D.A. (1986). The moderator-mediator variable distinction in social psychological research: Conceptual, strategic, and statistical considerations. Journal of Personality and Social Psychology, 51, 1173-1182.

Becker, J.L., Milad, M.P., \& Klock, S.C. (2006). Burnout, depression and career satisfaction: Cross sectional study of obstetrics and gynecology residents. American Journal of Obstetrics and Gynecology, 195, 1444-1449.

Biron, M., \& Bamberger, P. (2010). The impact of structural empowerment on individual well-being and performance: Taking agent preferences, self-efficacy and operational constraints into account. Human Relations, 63, 163-191.

Bliese, P.D. (2000). Within-group agreement, nonindependence, and reliability: Implications for data aggregation and analysis. In K.J. Klein \& S.W.J. Kozlowski (Eds.), Multilevel theory, research, and methods in organizations: Foundations, extensions and new directions (pp. 349-381). San Francisco, CA: Jossey-Bass.

Boamah, S.A., Read, E.A., \& Laschinger, H.K.S. (2017). Factors influencing new graduate nurse burnout development, job satisfaction and patient care quality: A time-lagged study. Journal of Advanced Nursing, 73, 1182-1195.

Bono, J.E., \& Judge, T.A. (2003). Self-concordance at work: Toward understanding the motivational effects of transformational leaders. Academy of Management Journal, 46, 554-571.

Borgersen, H.C., Hystad, S.W., Larsson, G., \& Eid, J. (2014). Authentic leadership and safety climate among seafarers. Journal of Leadership \& Organizational Studies, 21, 394-402.

Brislin, R.W. (1980). Translation and content analysis of oral and written material. In H.C. Triandis \& J.W. Berry (Eds.), 
Handbook of cross-cultural psychology: Vol. 2, Methodology (pp. 349-444). Boston, MA: Allyn and Bacon.

Carless, S. (2004). Does psychological empowerment mediate the relationship between psychological climate and job satisfaction? Journal of Business and Psychology, 18, 405-425.

Conger, J.A., \& Kanungo, R.N. (1988). The empowerment process: Integrating theory and practice. Academy of Management Review, 13, 471-482.

Dragoni, L. (2005). Understanding the emergence of state goalorientation in organizational work groups: The role of leadership and multilevel climate perceptions. Journal of Applied Psychology, 90, 1084-1095.

French, J.R.P. Jr., Rodgers, W., \& Cobb, S. (1974). Adjustment as person-environment fit. In G.V. Coelho, D.A. Hamburg, \& J.E. Adams (Eds.), Coping and adjustment (pp. 316-333). New York, NY: Basic Books.

Gardner, W.L., Avolio, B.J., Luthans, F., May, D.R., \& Walumbwa, F.O. (2005). 'Can you see the real me?' A self-based model of authentic leader and follower development. The Leadership Quarterly, 16, 343-372.

Harms, P.D., Credé, M., Tynan, M., Leon, M., \& Jeung, W. (2017). Leadership and stress: A meta-analytic review. The Leadership Quarterly, 28, 178-194.

Harrison, R.V. (1978). Person-environment fit and job stress. In C.L. Cooper \& R. Payne (Eds.), Stress at work (pp. 175-205). New York: Wiley.

Hildenbrand, K., Sacramento, C.A., \& Binnewies, C. (2018). Transformational leadership and burnout: The role of thriving and followers' openness to experience. Journal of Occupational Health Psychology, 23, 31-43.

Hmieleski, K.M., Cole, M.S., \& Baron, R.A. (2012). Shared authentic leadership and new venture performance. Journal of Management, 38, 1476-1499.

Hochwälder, J. (2007). The psychosocial work environment and burnout among Swedish registered and assistant nurses: The main, mediating, and moderating role of empowerment. Nursing and Health Sciences, 9, 205-211.

Hochwälder, J., \& Brucefors, A.B. (2005). Psychological empowerment at the workplace as a predictor of ill health. Personality and Individual Differences, 39, 1237-1248.

Hofmann, D.A., \& Stetzer, A. (1996). A cross-level investigation of factors influencing unsafe behaviors and accidents. Personnel Psychology, 49, 307-339.

Honkonen, T., Ahola, K., Pertovaara, M., Isometsä, E., Kalimo, R., Nykyri, E., Aromaa, A., \& Lönnqvist, J. (2006). The association between burnout and physical illness in the general population - Results from the Finnish Health 2000 Study. Journal of Psychosomatic Research, 61, 59-66.

Hsiung, H.H. (2012). Authentic leadership and employee voice behavior: A multi-level psychological process. Journal of Business Ethics, 107, 349-361.

Ilies, R., Morgeson, F.P., \& Nahrgang, J.D. (2005). Authentic leadership and eudaemonic well-being: Understanding leaderfollower outcomes. The Leadership Quarterly, 16, 373-394.

Kanter, R.M. (1993). Men and women of the corporation (2nd Eds.). New York, NY: Basic Books.
Karasek, R.A. Jr. (1979). Job demands, job decision latitude, and mental strain: Implications for job redesign. Administrative Science Quarterly, 24, 285-308.

Kiersch, C.E., \& Byrne, Z.S. (2015). Is being authentic being fair? Multilevel examination of authentic leadership, justice, and employee outcomes. Journal of Leadership \& Organizational Studies, 22, 292-303.

Kozlowski, S.W., \& Doherty, M.L. (1989). Integration of climate and leadership: Examination of a neglected issue. Journal of Applied Psychology, 74, 546-553.

Laschinger, H.K.S., Borgogni, L., Consiglio, C., \& Read, E. (2015). The effects of authentic leadership, six areas of worklife, and occupational coping self-efficacy on new graduate nurses' burnout and mental health: A cross-sectional study. International Journal of Nursing Studies, 52, 10801089.

Laschinger, H.K.S., Finegan, J., \& Shamian, J. (2001). Promoting nurses' health: Effect of empowerment on job strain and work satisfaction. Nursing Economics, 19, 42-52.

Laschinger, H.K.S., Finegan, J., Shamian, J., \& Wilk, P. (2001). Impact of structural and psychological empowerment on job strain in nursing work settings. Journal of Nursing Administration, 31, 260-272.

Laschinger, H.K.S., Finegan, J.E., Shamian, J., \& Wilk, P. (2004). A longitudinal analysis of the impact of workplace empowerment on work satisfaction. Journal of Organizational Behavior, 25, 527-545.

Laschinger, H.K.S., Wong, C.A., \& Grau, A.L. (2012). The influence of authentic leadership on newly graduated nurses' experiences of workplace bullying, burnout and retention outcomes: A cross-sectional study. International Journal of Nursing Studies, 49, 1266-1276.

Laschinger, H.K.S., Wong, C.A., \& Grau, A.L. (2013). Authentic leadership, empowerment and burnout: A comparison in new graduates and experienced nurses. Journal of Nursing Management, 21, 541-552.

Leiter, M.P., \& Maslach, C. (2004). Areas of worklife: A structured approach to organizational predictors of job burnout. Research in Occupational Stress \& Well Being, 3, 91-134.

Leroy, H., Anseel, F., Gardner, W.L., \& Sels, L. (2015). Authentic leadership, authentic followership, basic need satisfaction, and work role performance: A cross-level study. Journal of Management, 41, 1677-1697.

Li, C., Li, X., Shi, K., \& Chen, X. (2006). Psychological empowerment: Measurement and its effect on employee work attitude in China. Acta Psychologica Sinica, 38, 99-106.

Little, T.D., Cunningham, W.A., Shahar, G., \& Widaman, K.F. (2002). To parcel or not to parcel: Exploring the question, weighing the merits. Structural Equation Modeling, 9, 151173.

Luthans, F., \& Avolio, B. (2003). Authentic leadership: A positive development approach. In K.S. Cameron, J.E. Dutton, \& R.E. Quinn (Eds.), Positive organizational scholarship: Foundations of a new discipline (pp. 241-261). San Francisco, CA: Berrett-Koehler.

Mo, S., \& Shi, J. (2017). Linking ethical leadership to employee burnout, workplace deviance and performance: Testing the 
mediating roles of trust in leader and surface acting. Journal of Business Ethics, 144, 293-303.

Muthén, L.K., \& Muthén, B.O. (1998-2012). Mplus user's guide statistical analysis with latent variables (7th ed.). Los Angeles, CA: Author.

Naumann, S.E., \& Bennett, N. (2000). A case for procedural justice climate: Development and test of a multilevel model. Academy of Management Journal, 43, 881-889.

Parker, P.A., \& Kulik, J.A. (1995). Burnout, self-and supervisorrated job performance, and absenteeism among nurses. Journal of Behavioral Medicine, 18, 581-599.

Peterson, U., Demerouti, E., Bergström, G., Samuelsson, M., Åsberg, M., \& Nygren, Å. (2008). Burnout and physical and mental health among Swedish healthcare workers. Journal of Advanced Nursing, 62, 84-95.

Podsakoff, P.M., MacKenzie, S.B., Lee, J., \& Podsakoff, N.P. (2003). Common method biases in behavioral research: A critical review of the literature and recommended remedies, Journal of Applied Psychology, 88, 879-903.

Preacher, K.J., Zyphur, M.J., \& Zhang, Z. (2010). A general multilevel SEM framework for assessing multilevel mediation. Psychological Methods, 15, 209-233.

Rantika, S.D., \& Yustina, A.I. (2017). Effects of ethical leadership on employee well-being: The mediating role of psychological empowerment. Journal of Indonesian Economy and Business, 32, 121-137.

Read, E.A., \& Laschinger, H.K.S. (2015). The influence of authentic leadership and empowerment on nurses' relational social capital, mental health and job satisfaction over the first year of practice. Journal of Advanced Nursing, 71, 1611-1623.

Schermuly, C.C., \& Meyer, B. (2016). Good relationships at work: The effects of Leader-Member Exchange and Team-Member Exchange on psychological empowerment, emotional exhaustion, and depression. Journal of Organizational Behavior, 37, 673-691.

Schneider, B., Parkington, J.J., \& Buxton, V.M. (1980). Employee and customer perceptions of service in banks. Administrative Science Quarterly, 25, 252-267.

Seibert, S.E., Silver, S.R., \& Randolph, W.A. (2004). Taking empowerment to the next level: A multiple-level model of empowerment, performance, and satisfaction. Academy of Management Journal, 47, 332-349.

Shapira-Lishchinsky, O., \& Tsemach, S. (2014). Psychological empowerment as a mediator between teachers' perceptions of authentic leadership and their withdrawal and citizenship behaviors. Educational Administration Quarterly, 50, 675712 .
Spreitzer, G.M. (1995). Psychological empowerment in the workplace: Dimensions, measurement, and validation. Academy of Management Journal, 38, 1442-1465.

Spreitzer, G.M. (1996). Social structural characteristics of psychological empowerment. Academy of Management Journal, 39, 483-504.

Sun, L.-Y., Zhang, Z., Qi, J., \& Chen, Z.X. (2012). Empowerment and creativity: A cross-level investigation. The Leadership Quarterly, 23, 55-65.

Thomas, K.W., \& Velthouse, B.A. (1990). Cognitive elements of empowerment: An 'interpretive' model of intrinsic task motivation. Academy of Management Review, 15, 666-681.

Tuuli, M.M., \& Rowlinson, S. (2009). Empowerment in project teams: A multilevel examination of the job performance implications. Construction Management and Economics, 27, 473-498.

Wallach, V., \& Mueller, C. (2006). Job characteristics and organizational predictors of psychological empowerment among paraprofessionals within human service organizations. Administrations in Social Work, 30, 95-113.

Walumbwa, F.O., Avolio, B.J., Gardner, W.L., Wernsing, T.S., \& Peterson, S.Z. (2008). Authentic leadership: Development and validation of a theory-based measure. Journal of Management, 34, 89-126.

Walumbwa, F.O., Wang, P., Wang, H., Schaubroeck, J., \& Avolio, B.J. (2010). Psychological processes linking authentic leadership to follower behaviors. The Leadership Quarterly, 21, 901-914.

Wang, X., Zhang, Y., Gan, Y., \& Zhang, Y. (2005). Development of job-burnout inventory for middle school teachers. Chinese Journal of Applied Psychology, 11, 170-175.

Yang, M., \& Fry, L.W. (2018). The role of spiritual leadership in reducing healthcare worker burnout. Journal of Management, Spirituality \& Religion, 15, 305-324.

Zhang, J., Song, L.J. Wang, Y., \& Liu, G. (2018). How authentic leadership influences employee proactivity: The sequential mediating effects of psychological empowerment and core self-evaluations and the moderating role of employee political skill. Frontiers of Business Research in China, 12. https://doi.org/10.1186/s11782-018-0026-X

Zhang, Z., Zyphur, M.J., \& Preacher, K.J. (2009). Testing multilevel mediation using hierarchical linear models: Problems and solutions. Organizational Research Methods, 12, 695719.

Zohar, D., \& Tenne-Gazit, O. (2008). Transformational leadership and group interaction as climate antecedents: A social network analysis. Journal of Applied Psychology, 4, 744-757. 